\title{
S.M. Levytskyi
}

\section{Influence of Laser Radiation on Optical Transparent Dielectrics}

\author{
V.E. Lashkaryov Institute of Semiconductor Physics NAS of Ukraine, Kyiv, Ukraine, levytskyi@ua.fm
}

\begin{abstract}
This paper deals with the main characteristics of the influence of pulsed laser radiation and its application for the labeling of transparent dielectrics. On the basis of the analysis of the literature data and the study of the possibilities of using laser radiation for marking different materials, it is proposed to investigate the effect of the radiation wavelength on the size of the received defect inside the material. Experimentally shown that the pulse laser processing of samples with laser irradiation energy below $3.4 \mathrm{~mJ} / \mathrm{cm}^{2}$ visual tags in the sample are not formed. This way allow to control the geometric dimensions of the label.
\end{abstract}

Keywords: marking, dielectric, glass, polymers, laser irradiation.

Received 04 April 2020; Accepted 15 June 2020.

\section{Introduction}

The effect of laser radiation on materials has been studied since the creation of lasers. Due to the continuous development of technology, lasers are the most commonly used to process virtually any material. One of the promising areas of development in the field of laser technologies is marking, thanks to its demand almost everywhere. Currently, the most common labeling materials are dielectrics. These include glass materials, polymers, precious stones, etc.

The principles of marking and mechanisms that explain the essence of the process are still being studied. A variety of mechanisms and models explaining the essence of the interaction of laser radiation with matter is very large, but so far no general systematics has been found for selecting parameters and explaining what is happening inside the material depending on certain conditions [1-6].

\section{Theoretical background}

To date, the literature discusses a number of possible mechanisms and models of the destruction of transparent materials of different class under the influence of laser pulses. A general analysis of all available data for materials such as glass, gemstones and polymers has been performed.
According to the prevailing ideas, the local laser modification of transparent solids can be caused by various mechanisms of absorption of laser radiation energy. Among them are noted the so-called intrinsic mechanisms associated with the properties of the matrix itself (impact and multiphoton ionization), which are possible only under the influence of ultrashort pulses; and mechanisms caused by absorbing defects (thermoelastic, photoionization, etc.), realized in the region of long pulses [7]. The implementation of this or that mechanism of destruction (thermal/non-thermal) depends on a large number of factors: the purity of the studied samples, the wavelength of the laser, the duration of the laser pulse, the frequency of the pulse repetition, the focusing parameters, etc. However, both are often implemented. The degrees of their influence on the result of the process are also different. In this regard, in order to clarify the dominant fracture mechanism for each specific case of material processing, it is preferable to be able to quickly change the values of the indicated radiation and focusing parameters from milliseconds to femtoseconds. Currently, it is much more common to use lasers with a short duration of the radiation pulse (from the nanosecond range and below) for marking inside the material, therefore, in the future we will take into account precisely these pulse durations.

Based on the literature data [8], three thermal models can be distinguished that describe the interaction of laser radiation with the material. 
1). Long pulses comparable to relaxation time (less than $1 \mathrm{~ms}$ ). It is characterized by photothermal ablation (heat is distributed due to thermal conductivity) and evaporation of the material with boiling after primary melting. However, such thermal exposure may cause material removal. Non-thermal effects include mechanical stress and photochemical ablation, i.e. in some cases, the photon energy is sufficient for the direct destruction of chemical bonds without heat input.

2). Shorter thermal equilibrium pulses still persist, but the heat loss is directed to evaporation (less than 1 ns). With this action, heating occurs, described by a quadratic function, and cooling, described by a logarithmic function. Some steps, inside the description of this function, are caused by latent thermal effects. The process of processing with nanosecond pulses is based on the formation of plasma in its process, resulting in a gradual formation of an impact crater.

3). Ultrashort pulses that are small compared with the relaxation times of the structure. Such an effect leads to non-thermal equilibrium with electrons and a lattice having different temperatures, with direct evaporation and the Coulomb effect (less than $1 \mathrm{ps}$ ). The essence of the process is to remove material without significantly heating nearby areas. In this case, the thermal concepts are not applicable.

Thus, each case has its own laws that must be considered when processing materials. If we talk about direct interaction with an absorbing medium, then the light flux partially reflects from the surface, and partially penetrates into the material, being absorbed in it. Change in light flux density $q$, i.e. the amount of light energy per unit surface area of a material per unit time in an absorbing medium is described by the Bouguer-Lambert law:

$$
q(x)=q_{0} A e^{-\int_{0}^{x} a(x) d x},
$$

where $q_{0}$ is the density of the incident light flux on the surface of the material, $A$ - absorptivity of the material, $A=1-R(R-$ reflection coefficient); $a(x)$ - the absorption coefficient of light in the medium. The $x$ coordinate is counted from the surface into the material.

The specific values of the quantities $A$ and $\alpha$ included in formula (1), as well as the mechanisms of light absorption and its transition to heat, are different for all materials. So, for example, the values of the reflection and absorption coefficients depend on the radiation wavelength. Using formula (1), it is always possible to theoretically verify the level of energy input at given depths of the material, which is an integral part in the design of experiments and their direct conduct. However, it should be borne in mind that when using the BouguerLambert law, only linear absorption in a homogeneous material is taken into account, as a result of which the mechanisms causing non-linear behavior are neglected. This can be avoided by making some assumptions indicated in [9].

\section{Experimental results and their discussion}

In order to obtain the markers, it is necessary to focus the laser beam using optical systems (lenses, etc.). The laser beam focusing scheme is shown in Fig. 1.

Because of the imperfection of optical systems, it is impossible to focus the beam at a mathematical point, there is a finite limit of focus that is called diffraction and determines the minimum focal spot area.

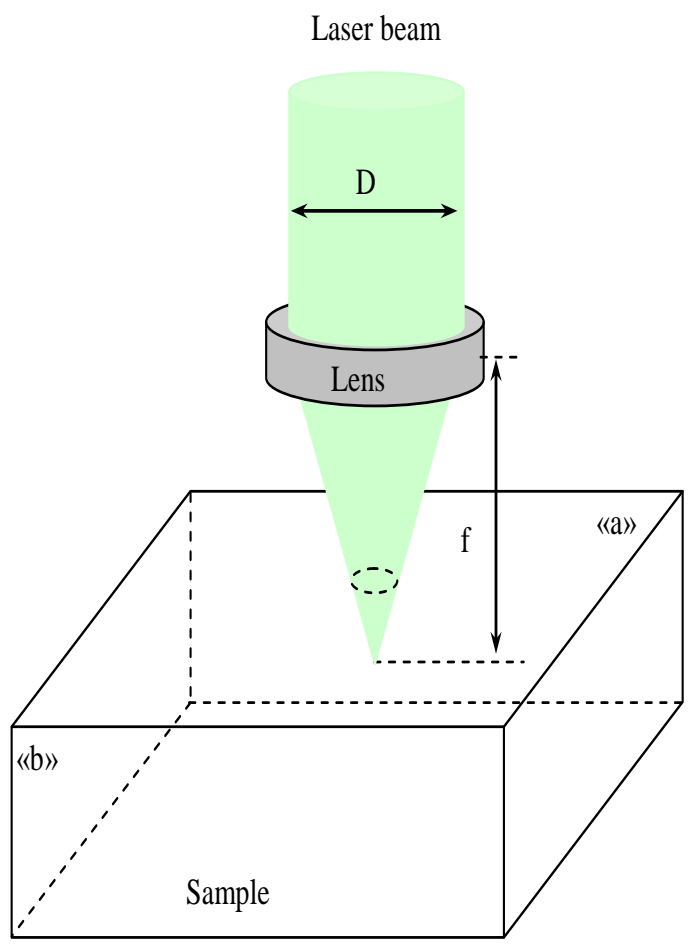

Fig. 1. The laser beam focusing scheme.

In our case, a light Gaussian beam with a circular section is used. If such a beam focuses on the optical axis of the lens with a focal length $f$, then the minimum achievable diameter of the focused spot $\mathrm{d}_{0}$ is determined by the expression:

$$
d_{0}=1,22 \lambda f / D
$$

where $\lambda$ is the wavelength of the radiation; $f$ - focal length, $D$ - the width of the focused laser beam.

It is advisable to use a short-focus lens to obtain a sufficiently small diameter of focused beam, that is, high system resolution. But in practice, large-format scanning fields have to use long-focused lenses, which increase the focus beam size. Another possibility to reduce the diameter of the scanning beam and thereby increase the resolution of the system is to increase the width $D$ of the laser beam incident on the lens. An important characteristic of the focusing system is the depth of field.

The laser beam transformed by the optical system has the shape of a hyperboloid of rotation with a diameter $d_{0}$ of the beam constriction in the focusing area (Fig. 2).

The constriction can be characterized by a 


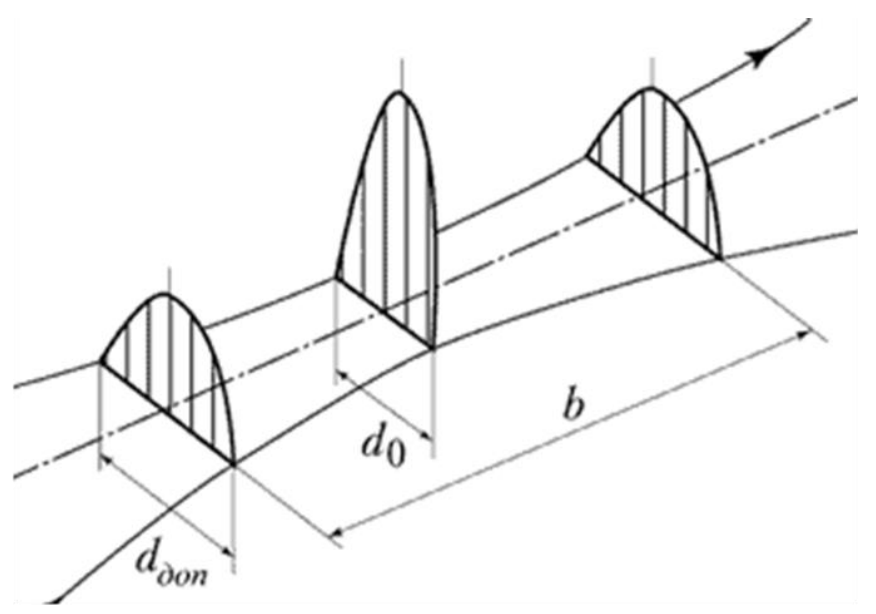

Fig. 2. The nature of the intensity distribution of laser radiation in different sections of the focused laser beam.

longitudinal distribution $b$, within which the beam diameter varies slightly:

$$
b=3,6 \lambda f^{2} \sqrt{\varepsilon} / D^{2},
$$

where $D$ is the diameter of the beam at the entrance to the optical system. Parameter $b$ can be considered as the depth of focus or depth of field of the focusing system, at which the relative magnitude of the change in diameter of the focused beam is determined by the expression:

$$
\varepsilon=\left(d_{\partial o n}-d_{0}\right) / d_{0}
$$

On the other hand, the depth of field can be approximated by the ratio:

$$
b=\lambda f^{2} / R_{L}^{2},
$$

where $\lambda$ is the wavelength, $R_{L}$ is the lens radius, $f$ is the focal length.

The dependence of the focused beam diameter $\left(d_{0}\right)$ and the depth of field $(b)$ on the laser wavelength is shown in Fig. 3.

The marks in the sample (K8 optical glass) were obtained as a result of irradiation of a neodymium laser
( $\lambda=532 \mathrm{~nm})$ of nanosecond duration $(\tau=7-8 \mathrm{~ns})$ with an energy density of $E$ from 250 to $3.4 \mathrm{~mJ} / \mathrm{cm}^{2}$. Irradiation was carried out at room temperature $(\mathrm{T}=300 \mathrm{~K})$.

Taking into account the parameters of the optical system, we get the diameter of the focused beam $\left(d_{0}\right)$ in focus, which is $1.03 \cdot 10^{-5} \mathrm{~m}$, and the depth of field (b) $-8.34 \cdot 10^{-6} \mathrm{~m}$

One of the critical parameters that determines the appearance and size of fracture in the bulk and on the reliability of the transparent material is the absorbed energy of radiation. It is related to the size of the destruction and the energy spent to destroy it. The calculation of the energy absorbed on the surface of the sample is calculated by the following formulas:

$$
\begin{gathered}
\mathrm{E}_{\text {nor }}=(1-\mathrm{R}) \mathrm{E}_{\text {пад }} e^{-\mathrm{ax}} \\
\mathrm{E}_{\text {пад }}=\mathrm{E}_{\mathrm{Las} / \mathrm{S}_{\text {fok }}} \\
\mathrm{S}_{\text {fok }}=\left(\pi \mathrm{d}_{0}^{2}\right) / 4
\end{gathered}
$$

In Fig. 4 shows the markers, depending on the

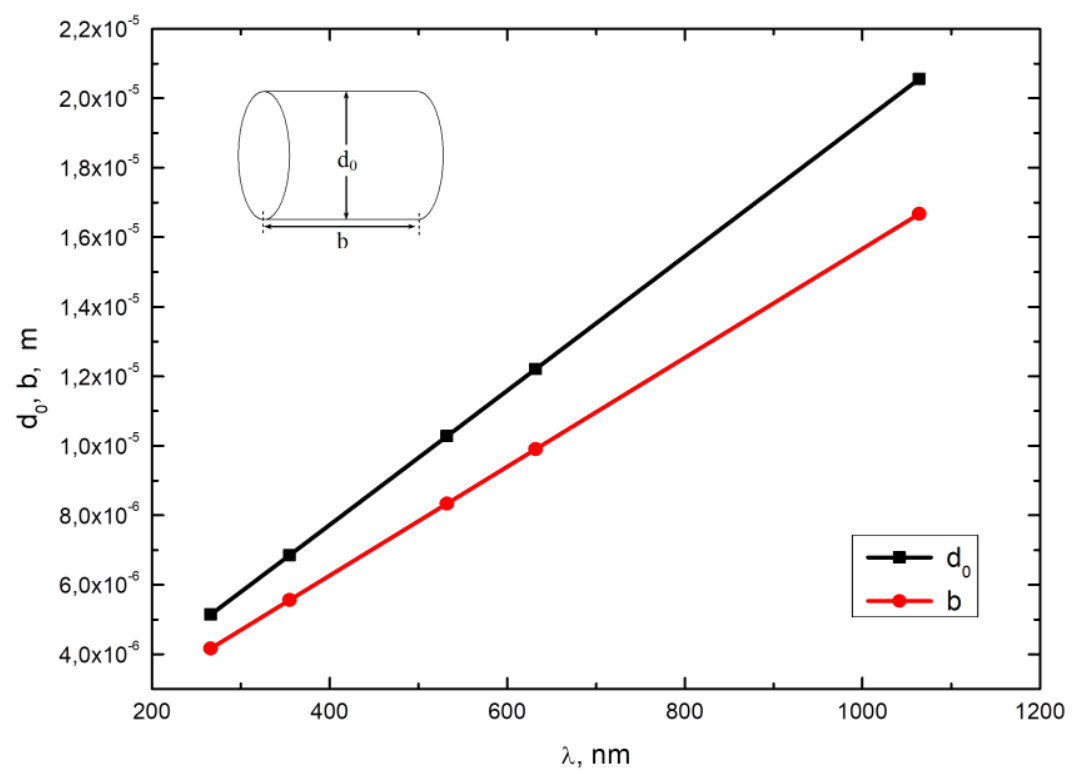

Fig. 3. Dependence of the focused beam diameter $\left(d_{0}\right)$ and depth of field $(b)$ on the laser irradiation wavelength. 


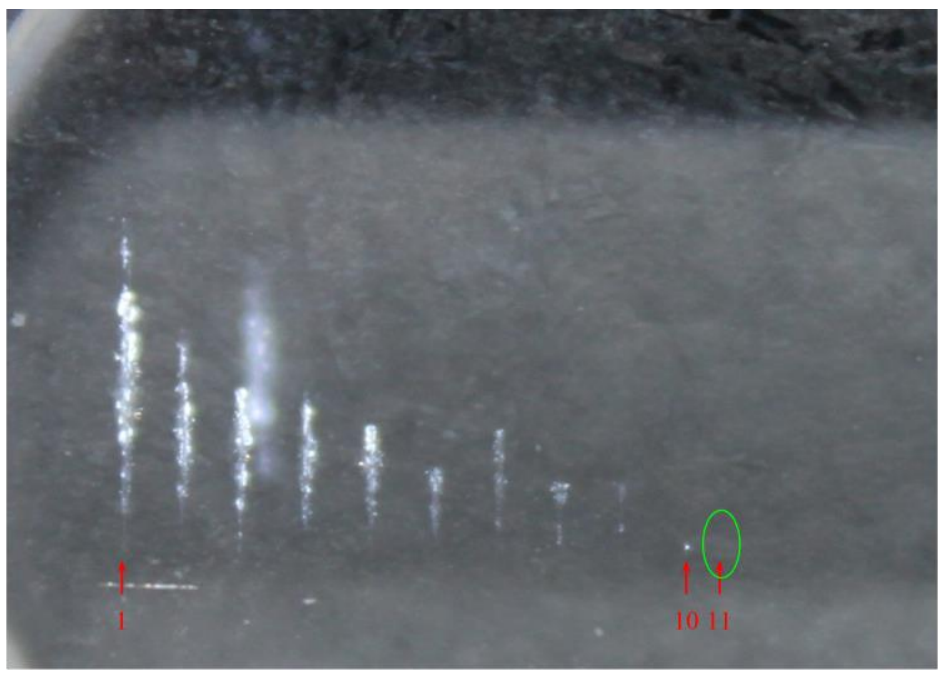

Fig. 4. Markers depending on the change in the laser energy density.
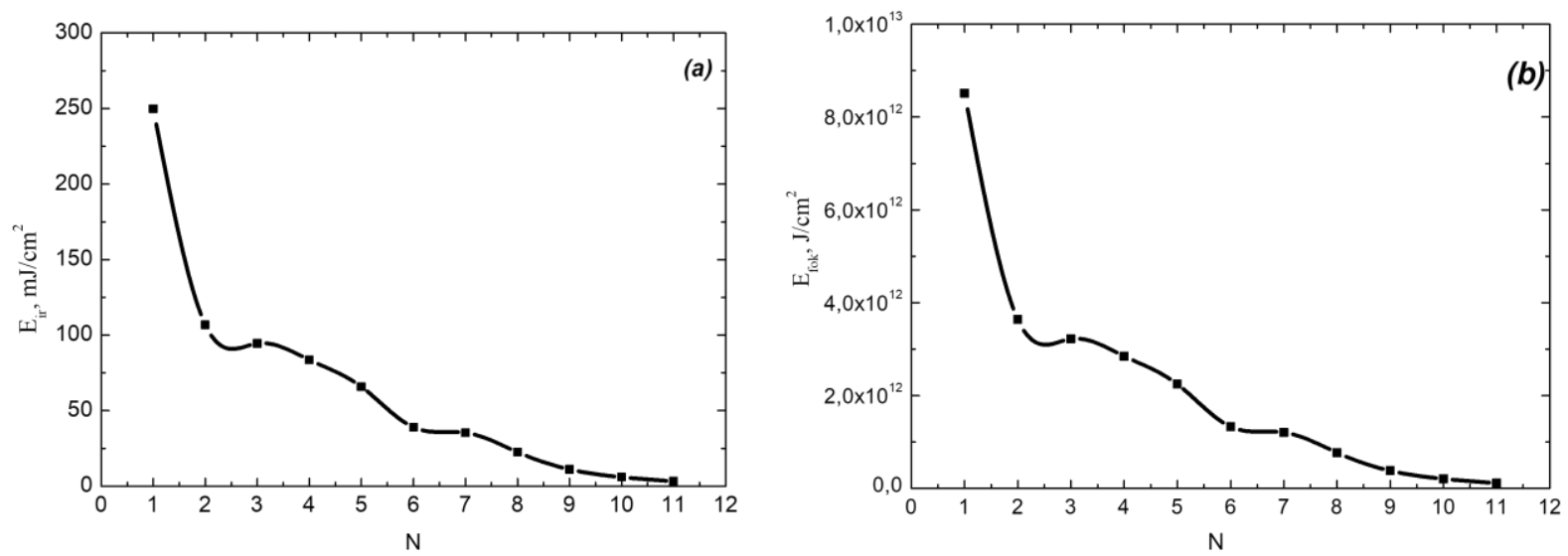

Fig. 5. Changing the energy density of the laser radiation from the irradiation number (a), and changing the energy density of the focused beam, in focus, depending on the label number (b).

change in the laser energy density (reduction of energy from left to right).

In Fig. 5 a shows the change in the laser energy density from the irradiation number (label number), and the change in the laser radiation energy density of the focused beam, in focus, depending on the label number (Fig. 5 b).

From the above results it can be concluded that at the laser irradiation energy of $3.4 \mathrm{~mJ} / \mathrm{cm}^{2}$ (with a focal energy of $1.2 \cdot 10^{11} \mathrm{~J} / \mathrm{cm}^{2}$ ) visual marks are not formed in the sample. It can also be concluded that as the laser wavelength decreases, the label size will decrease (namely, the focused beam diameter and depth of field). Thus, you can control the geometric dimensions of the label.

In addition to the fracture criteria, one should consider the temporal parameters and characteristics of laser radiation that affect the result of the interaction of radiation with the material. These include the pulse duration $\tau$ and the temporary pulse shape $I(\tau)$. The duration of the radiation pulse in the case of radiation processing of transparent brittle materials can only affect the morphology of destruction.

It should be borne in mind that the processing of the material occurs through multipulse processing. It should be considered in two cases: 1) upon irradiation of a material with a power density insufficient to modify the material (subthreshold), 2) with a power density exceeding the threshold for the destruction of the material [10].

The strength of many transparent brittle materials in the regime of multipulse laser irradiation is usually much lower than their strength under single-pulse laser irradiation. Such a decrease in resistance to date has been found in materials of various types: in silicate glasses, crystals, and even polymers. The physical reasons for the decrease in strength in the regime of multiple irradiation can be related both to the probabilistic nature of failure and to the accumulation of irreversible changes in the material under the influence of radiation.

At radiation intensities below the threshold, a catastrophic increase in the absorption and destruction of the material in one pulse does not occur. At the same time, irreversible changes can occur in it, due to dynamic and residual thermoelastic stresses [10].

Thus, under the influence of intense laser radiation in a multi-pulse mode, destruction occurs in the material due to tensile, residual thermoelastic and dynamic 
stresses.

\section{Conclusions}

Experimental studies have shown that visual pulses are not formed in the sample by pulsed laser treatment of the samples with laser irradiation energy below $3.4 \mathrm{~mJ} / \mathrm{cm}^{2}$. It can also be concluded that as the laser wavelength decreases, the label size will decrease (namely, the focused beam diameter and depth of field). Thus, you can control the geometric dimensions of the label.

Levytskyi S.M. - Senior science specialist in optics of optoelectronic devices.

[1] Y.K. Danileiko, A.A. Manenkov, V.S. Nechitaylo, Proceedings of FIAN 101, 31 (1978).

[2] A.A. Manenkov, A.M. Prokhorov, UFN 148(1), 179 (1986).

[3] N.B. Delone, The interaction of laser radiation with a substance: A course of light (Science, Moscow, 1989).

[4] M.F. Koldunov, A.A. Manenkov, I.L. Pokotilo, Quantum Electronics 32(7), 623 (2002) (https://doi.org/10.1070\%2FQE2002v032n07ABEH002258).

[5] K.D. Kanev, P.V. Gnatyuk, V.A. Gnatyuk, Advanced Materials Research 222, 78 (2011) (https://doi.org/10.4028/www.scientific.net/AMR.222.78).

[6] V.A. Gnatyuk, O.I. Vlasenko, S.N. Levytskyi, S.V. Gagarsky; K.S. Zelenska, L.V. Poperenko, T. Aoki, Photonics Technologies, 2014 Fotonica AEIT Italian Conference on, (2014) (DOI: 10.1109/Fotonica.2014.6843885),

[7] M.F. Koldunov, A.A. Manenkov, I.L. Pokotilo, Quantum Electronics 25, 3 (1998) (https://doi.org/10.1070\%2FQE1998v028n03ABEH001179)

[8] W.M. Steen, Laser Material Processing (Springer, Jyotirmoy Mazumder, 2010).

[9] J. Bosman, Processes and strategies for solid state Q-switch laser marking of polymers (Velden, Netherlands, 2007).

[10] V.A. Gnatyuk, O.I. Vlasenko, S.N. Levytskyi, T.Aoki, V. Mizeikis, S.V. Gagarsky, K.S. Zelenska, D.V. Gnatyuk, Journal of Laser Micro/Nanoengineering 11(2), 164 (2016) (DOI: 10.2961/jlmn.2016.02.0005).

\title{
С.М. Левицький
}

\section{Вплив лазерного опромінення на оптично прозорі діелектрики}

\author{
Інститут фізики напівпровідників ім. В.С. Лашкарьова НАН Украӥни, м. Київ, Украӥна, levуtskуі@иа.fm
}

\begin{abstract}
Дана робота присвячена ключовим характеристика впливу імпульсного лазерного випромінювання та застосування його для маркування прозорих діелектриків. На основі аналізу літературних даних та вивчення можливостей застосування лазерного випромінювання для маркування різних матеріалів пропонується дослідити вплив довжини хвилі випромінювання на розмір отриманого дефекту всередині матеріалу. Експериментально показано, що при імпульсній лазерній обробці досліджуваних зразків із енергією лазерного опромінення нижче 3,4 мДж/см² візуальні мітки в зразку не утворюються. Тим самим можна контролювати геометричними розмірами мітки.
\end{abstract}

Ключові слова: маркування, діелектрик, скло, полімери, лазерне опромінення. 